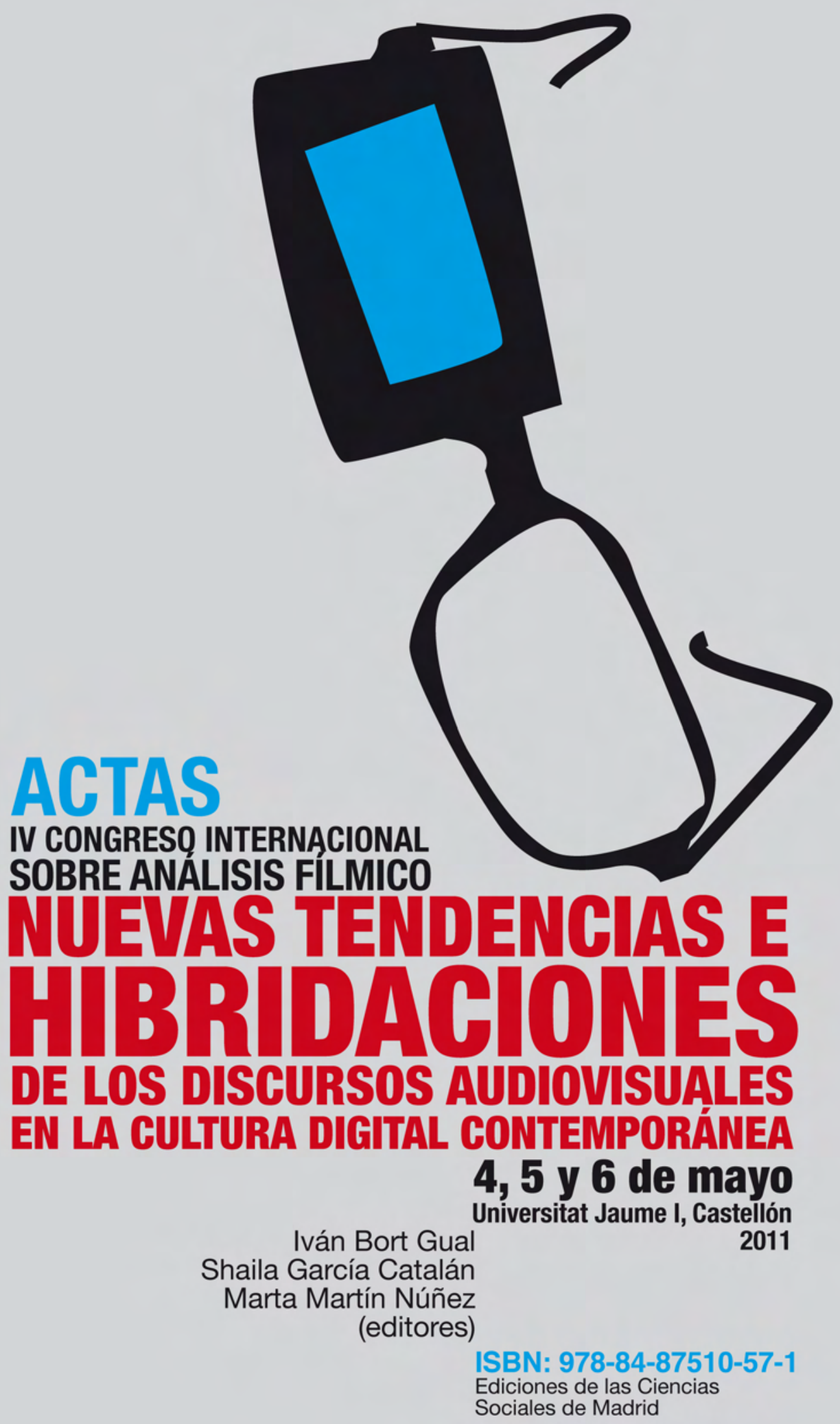




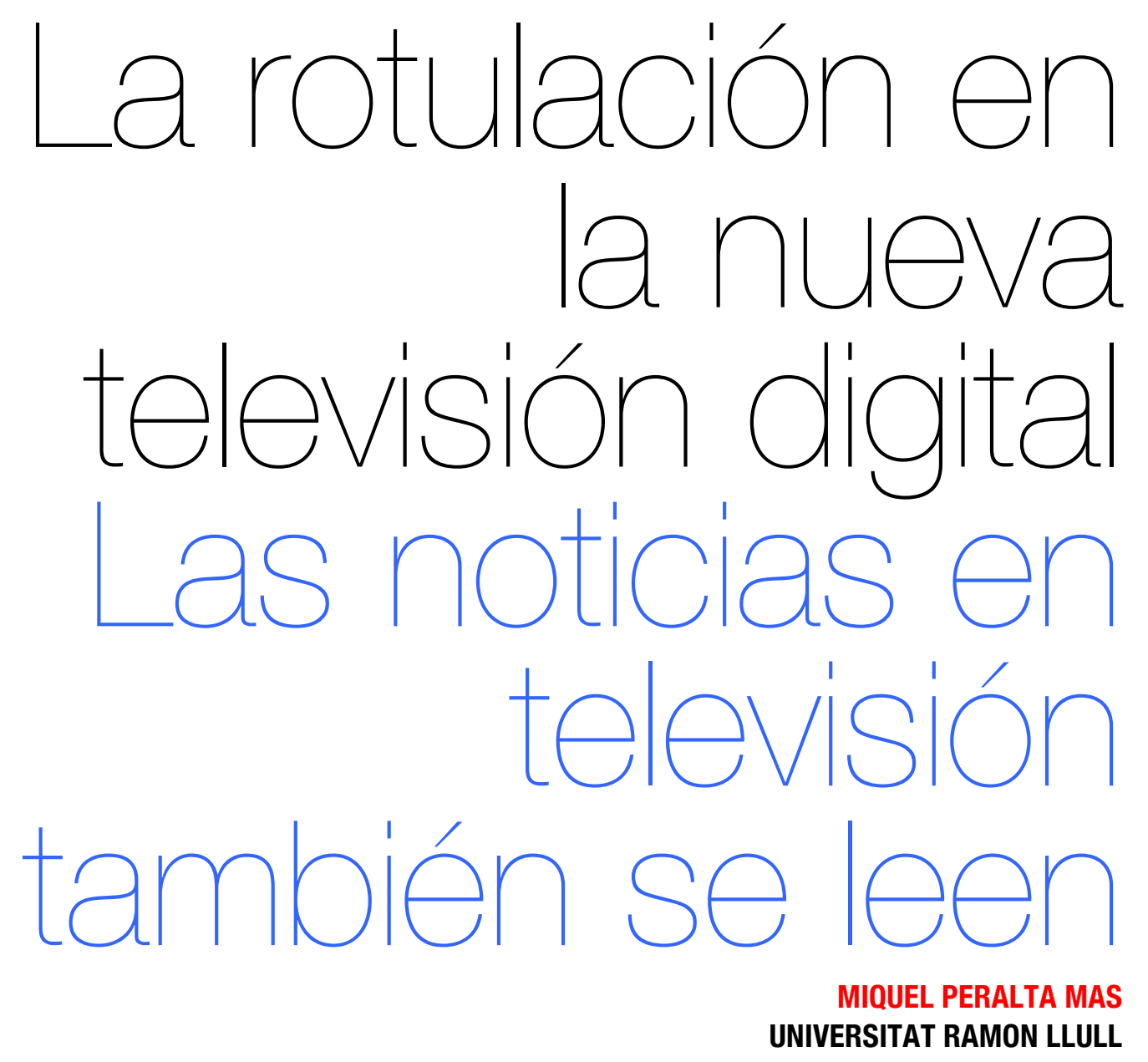


Las nuevas tecnologías y muy especialmente la digitalización del proceso de producción de las noticias de los teleinformativos modifican permanentemente la concepción y elaboración de las noticias en televisión. También están transformando la redacción y el propio lenguaje de la noticia televisiva. Se trata de un fenómeno paulatino y persistente, casi imperceptible, pese a que trasciende a la propia noción de la noticia e implica a todos los profesionales que la elaboran.

La redacción digital, con el sistema de edición no lineal al frente, ha transformado el modo de trabajar de los periodistas, de los realizadores y de los técnicos de televisión. El paso del sistema analógico al digital ha permitido una grabación y una posterior edición más ágil de la noticia, una mejor calidad de la imagen y del sonido, una mayor maniobrabilidad de los profesionales en los desplazamientos en zonas de conflictos bélicos, y más y mejores posibilidades de expresión visual de las imágenes — fundidos, encabalgamientos, entradillas...-.

En el ámbito de los programas televisivos de actualidad ha facilitado la creación de nuevos formatos de expresión en la televisión concretados en iniciativas interesantes como Españoles en el mundo (TVE), Callejeros (Cuatro) o Jutjats y Efecte mirall (TV3). Se trata de programas muy distintos pero que han sido líderes de audiencia, a caballo entre el entretenimiento y la divulgación. Su emisión regular en algunas de las grandes cadenas generalistas ha posibilitado una alternativa de calidad —aunque con altibajos - en horarios de máxima audiencia, demostrando asimismo que la audiencia es capaz de apostar por una programación interesante frente a los programas basura —que los hay-. La emisión de estos nuevos formatos ha permitido a la opinión pública conocer nuevas personas, nuevas ciudades del mundo, distintos modos de vida y descubrir el funcionamiento de instituciones, de difícil acceso a los medios de comunicación y muy cerradas en si mismas, como los juzgados, los hospitales o las cárceles. La agilidad de los equipos de grabación y edición se ha trasladado, en estos casos, a la propia emisión y concepción de los reportajes.

La historia de la televisión está íntimamente ligada al desarrollo tecnológico, a pesar de que los avances en el ámbito científico y técnico siempre estén en un segundo plano, encubiertos por el poder de la imagen y del mensaje.

\section{El auge de la infografía}

con la nueva

televisión digital, la televisión no sólo se ve y se escucha, sino que también se lee

Esta comunicación se ciñe exclusivamente al ámbito de la noticia diaria en televisión y a los teleinformativos, es decir, a los programas informativos diarios de televisión. Su objetivo principal es demostrar, en una primera fase de investigación, que las nuevas tecnologías y la entrada de la digitalización en las redacciones de televisión están transformando el lenguaje y la expresión de las noticias, entendiendo por lenguaje el "estilo y modo de hablar y escribir de cada persona en particular" y por expresión "aquello que en un enunciado lingüístico manifiesta los sentimientos del hablante", según definiciones propias del Diccionario de la Real Academia de la Lengua Española. 
Nuestro enunciado es claro: una de las novedades que implican estos nuevos lenguajes digitales es la multiplicación de frases y expresiones escritas en la pantalla del televisor. A nuestro entender son cada vez más abundantes los rótulos visuales con oraciones, enunciados, incluso sólo con palabras que aparecen sobre impresionados en las noticias y en la propia emisión de los teleinformativos. Estos rótulos escritos en la pantalla complementan o refuerzan el mensaje periodístico y el contenido audiovisual. En este sentido la conclusión también es clara: la televisión no sólo se ve y se escucha, sino que también se lee. Se lee la pantalla del televisor. Pongamos varios ejemplos. Cada vez es más habitual que en determinados programas en directo mientras el presentador o presentadora realiza una entrevista vayan apareciendo en pantalla frases o expresiones a modo de titulares que son consecuencia de las respuestas de la persona entrevistada. Es una técnica muy usada en los magazines informativos de primera hora de la mañana como Los desayunos de TVE o Els matins de TV3. Una de las ventajas de esta nueva aplicación, efectos visuales e informativos aparte, es que el telespectador puede seguir lo más significativo de una entrevista sin necesidad de ser escuchada: en un bar o restaurante, en la oficina, en un despacho, en casa e incluso en los locutorios de radio donde en forma de tertulia periodistas y tertulianos comentan los hechos más destacados de ese día.

Otro caso distinto al anterior pero de resultado casi idéntico para la audiencia son los teleinformativos de las cadenas "al news" o "todo noticias". Se trata de los rótulos que a modo de sinfín aparecen en dichos canales de televisión en la parte inferior de la pantalla en una acentuada franja cromática. En dicha franja se suceden ininterrumpidamente todos los titulares más destacados del momento con el objetivo expreso de que sean leídos a través de la pantalla. Todo ello de forma autónoma a la noticia que se esté emitiendo en ese momento. En un teleinformativo pongamos por caso, el Canal 24 Horas de TVE o el 3/24 de Televisió de Catalunyapueden estar informando de un partido de fútbol y en la franja sinfín se puede leer la última cotización del euro respecto al dólar estadounidense.

El auge de la rotulación de oraciones y expresiones escritas en la pantalla de nuestro televisor no es un fenómeno aislado en el ámbito de la comunicación. En la prensa escrita y fundamentalmente en el inmenso espacio del ciberperiodismo el incremento de la infografía en las noticias y reportajes es un hecho incuestionable, según ha puesto de manifiesto en diversas investigaciones José Luís Valero, de la Universidad Autónoma de Barcelona. Pese a ello Valero, autor de diversas publicaciones sobre la materia, aclara bien que cantidad no es sinónimo de calidad y que la infografía «también es a menudo un conjunto gráfico lleno de copias consentidas no referenciadas, estéticas absurdas poco conectadas con la realidad y falsedades documentales importantes...»".

\section{Noticias digitales}

No abundan estudios académicos sobre la rotulación de la noticia en la televisión digital actual. Es por ello que creemos útil para ésta y posteriores investigaciones establecer al menos dos niveles de análisis, a modo de pautas metodológicas. El primer nivel de estudio tiene en cuenta unas características generales básicas

\footnotetext{
1 VALERO, José Luís (2010): "La infografía periodística y documental impresa" http://www.portalcomunicacion.com/esp/n_aab_lec_pdf.asp?id_llico=55
} 
según las funciones y particularidades de los rótulos. El segundo nivel de análisis pretende constituir una tipología fundamental de los principales rótulos que se usan actualmente en los teleinformativos diarios en España.

Respecto al primer nivel de estudio hemos establecido cuatro grados de asociación.

1. En primer lugar debemos entender los rótulos como una parte integrante e imprescindible de la noticia. Su aplicación garantiza una información completa, con todos los elementos necesarios para una buena comprensión del mensaje informativo. Su ausencia o su uso incorrecto es motivo de turbación por parte de la audiencia con lo que la noticia y el propio teleinformativo pierden credibilidad.

2. En segundo lugar debemos entender a los rótulos como elementos complementarios entre sí. A menudo es factible e incluso aconsejable su uso simultáneo en la misma pantalla. Identificar al mismo tiempo al periodista con su nombre, en el lugar dónde está informando y destacando que la conexión es en directo fortalece el discurso informativo. Sabemos quién informa, desde dónde, y observamos que lo hace en tiempo real. Es decir, la audiencia es informada desde el lugar de los acontecimientos y en el mismo momento en que éstos se producen.

3. En tercer lugar, la rotulación es un elemento identificativo y estético muy significativo para los teleinformativos y también para las propias cadenas de televisión. Cada canal tiene su propia imagen corporativa a través de numerosos elementos visuales como el logotipo, el color, una línea maestra de grafismo, una sintonía y sus variantes, un tipo concreto de enunciados y rótulos, los propios presentadores y caras conocidas... Mantener una cierta homogeneidad de esta imagen corporativa en los teleinformativos y en sus noticias ayuda a la audiencia a situarse en el canal escogido.

4. En cuarto lugar, queremos destacar que los avances en el terreno de la infografía antes mencionados, amén de las distintas y nuevas aplicaciones entorno al diseño asistido por ordenador, están transformando el universo visual de los medios de comunicación, enriqueciéndolo. A pesar de que pueda haber casos contradictorios que lleguen a falsear y adulterar el mensaje, es necesario apostar por las nuevas tecnologías también en el ámbito de la elaboración de las noticias y de los teleinformativos. Las denominadas multiplataformas son ya una realidad y hoy una gran parte de los periodistas de televisión deben reelaborar sus noticias emitidas por la televisión para las versiones electrónicas y de telefonía móvil del propio medio de comunicación. ${ }^{2} Y$ viceversa. $Y$ es que, paulatinamente, las versiones digitales de los periódicos van adquiriendo mayor protagonismo y mayor personalidad con respecto de sus hermanos mayores de letra impresa.

El segundo nivel de análisis pretende elaborar una tipología de los rótulos de las noticias y de los teleinformativos para facilitar su identificación y su función. Esta clasificación permitirá además establecer unas herramientas básicas para su estudio y posteriores investigaciones académicas. Una correcta catalogación es un factor positivo en cualquier estudio académico.

En este sentido, atendiendo a su función en la noticia y considerados los cuatro niveles de asociación arriba mencionados, los rótulos pueden clasificarse en nueve

2 Según la OJD, la web de RTVE obtuvo en diciembre de 2010, 10.216.624 usuarios. http://www.rtve.es/mediateca/videos/20110114/rtvees-cierra-2010-como-web-audiovisuallider/988350.shtml 
grupos: de situación, de temporalidad, de carácter identificativo; de carácter informativo; de presentación; de titulares -cabeceras, resúmenes y titulares finales-; de carácter estructural dentro del teleinformativo; de tipo publicitario y finalmente textuales, aquellos propios de una trascripción o una traducción, por ejemplo. Para terminar incluimos un décimo grupo que englobaría los rótulos de programas informativos de carácter excepcional.

1. De situación: son los rótulos que localizan territorialmente la acción o el acontecimiento: ("Barcelona").

2. De temporalidad: son aquellos rótulos que concretan el tiempo de la noticia o suceso. ("Barcelona, esta tarde"); (TN Directe/Badalona/Ariadna Oltra). Recordemos aquí la complementariedad de los rótulos.

3. Identificativos: Son aquellos que identifican a los protagonistas. ("Rafa Nadal, tenista"); (“Elena Salgado, vicepresidenta del Gobierno y ministra de Economía").

4. Informativos: son de diversa índole, pero mantienen un carácter eminentemente informativo. Generalmente son de dos tipos: aquellos que con sus enunciados en la pantalla amplían la información proporcionada por la noticia y aquellos otros que la destacan y refuerzan, sin que necesariamente los enunciados aporten mayores datos. ("Un hombre permanece 2 horas atrapado en su vehículo debido a una riada"); ("TN Directe/Badalona/Cues al migdia per poder votar") (Borussia Dortmund 2/Werder Bremen 0).

5. De presentación: generalmente se refieren a periodistas y profesionales del medio. ("Ana Blanco"); ("Lorenzo Milá, corresponsal Washington").

6. De titulares: son aquellos rótulos propios de los distintos bloques de titulares. A destacar que los titulares de un teleinformativo no se ubican únicamente al inicio y final del programa, sino que los encontramos a lo largo de su emisión, como por ejemplo antes y después de la publicidad o inmediatamente después de la cabecera a modo de presentaciones, incluso antes de que aparezcan en pantalla los conductores de los informativos. En estos últimos casos los conductores leen las presentaciones sin ser vistos en pantalla para aparecer seguidamente y dar paso al bloque de titulares más convencional. ("El régimen iraní trata de justificar la condena a Sakineh Ashtiani con una farsa televisiva"); ("Controladors: Els afectats s'organitzen”); (“Operación Galgo").

7. Estructurales: generalmente se trata de ráfagas y efectos divisorios de los bloques de noticias: "TN"; "Noticias de las 9"; "TD Telediario"; "TN/Els esports"; "A3/A fondo";"Espai Internet"; "Equipo de investigación TVE". El hecho de que algunos de ellos vayan acompañados de letra impresa nos aconseja incluirlos como rótulos, calificación que no invalida su estudio como elementos infográficos y visuales.

8. Publicitarios: hay cadenas que incluyen la autopromoción en sus teleinformativos: ("Tengo ganas de ti. Antena 3 Films producirá la segunda parte de "Tres metros sobre el cielo"”); ("Publicidad"); ("Más información en antena3.com/noticias).

9. Textuales: cada vez más a menudo las cadenas incluyen en la pantalla de los televisores las trascripciones literales de fragmentos de voz de los protagonistas de la noticia. Dicha práctica se da fundamentalmente en tres casos. En el primer caso la trascripción corresponde a declaraciones radiofónicas, que por diversas razones la televisión no dispone. En esas ocasiones se escribe en la pantalla lo que el telespectador ya puede oír por el televisor; con ello se consigue reforzar el mensaje 
oral pero la rotulación también disimula la falta de imagen del protagonista que habitualmente es sustituida por una fotografía digitalizada a un lado de la pantalla del televisor. En el segundo caso la rotulación también viene a sustituir la falta de imagen. Estas situaciones son frecuentes cuando los profesionales quieren informar de una sentencia judicial, por ejemplo, y no se dispone de la grabación televisiva pertinente. Asimismo este recurso también se utiliza en el caso de un parte médico, de una declaración institucional escrita de un responsable político o para destacar algún detalle literal de una cláusula de un contrato de un futbolista o deportista. ("Los tramposos han disfrutado de una impunidad desesperante para el resto de los deportistas, que se veían condenados a competir en inferioridad de condiciones, por el mero hecho de respetar las normas").

Otro caso, aunque no tiene la singularidad ni funcionalidad que tienen los rótulos a los que hemos hecho referencia hasta ahora, se referiría a aquellos planos que aparecen en las noticias y que se limitan a reproducir unos rótulos que son ajenos al medio de comunicación que realiza el teleinformativo. En estos casos su función es normalmente y simplemente ilustrativa, como una imagen más, aunque en esta ocasión dicha imagen incluya una rotulación o incluso un montaje infográfico. ("President Obama. Stay Strong-No millionaire Bailouts"); "Vote Jude Celestin.Prezidan.10").

10. Presentaciones excepcionales. Cabría un décimo grupo si tenemos en cuenta algunas excepciones propias de la información de actualidad. Pensemos, por ejemplo, en las sofisticadas y modernas presentaciones gráficas de los resultados electorales durante la noche de un día de elecciones. Los presentadores se pasean literalmente por encima de los gráficos y enunciados de todo tipo mientras comentan y valoran los escrutinios. Las nuevas tecnologías permiten, en este sentido, una mayor plasticidad de la rotulación y el grafismo.

Los avances tecnológicos y electrónicos también posibilitan una mayor interactividad entre la cadena y la audiencia. Esta tendencia, muy marcada en los medios de comunicación en versión electrónica por Internet, se refleja igualmente en los noticiarios. Así es fácil observar que una cadena plantee una breve encuesta entre los telespectadores. Los resultados de dicha consulta se expresarán en la pantalla a través de enunciados, rótulos y gráficos numéricos.

\section{Rótulos digitales}

Tipificados los rótulos llega la hora de investigar la posición de los mismos en las noticias de los informativos diarios. La falta de bibliografía y estudios sobre la materia nos obliga, como en el capítulo anterior, a una perspectiva metodológica.

En el apartado anterior hemos intentado responder a unas preguntas básicas: ¿Cómo son los rótulos de las noticias de televisión?, ¿qué dicen? y ¿cómo lo dicen? El segundo nivel de análisis que abordamos a partir de ahora debería dar contestación a otro tipo de preguntas, quizá menos llamativas, pero igualmente significativas. Por ejemplo, ¿cuánto tiempo permanecen los rótulos en pantalla?, ¿en qué lugar de la pantalla aparecen? y ¿Qué tamaño y tipo de letra usan?

Cabe advertir de antemano que cada cadena de televisión define unos rasgos y características propias que la definen, la dotan de una personalidad y una imagen de marca determinadas. Dentro de estas líneas maestras cada programa tiene sus particularidades que también lo identifican para con la audiencia. $Y$ del mismo modo los teleinformativos poseen una estrategia de identificación y fidelización de 
los telespectadores. Incluso podemos advertir un cuarto nivel de observación por cuanto los programas informativos son distintos entre sí, según sus diversas ediciones. No hablamos en este caso de los contenidos informativos, sino de la visualización del teleinformativo. Por ejemplo, en los noticiarios de la noche -aquellos que se emiten a las 20,30 o a las 21,00 horas, según las cadenas- los presentadores tienen mayor peso dentro del programa que en los teleinformativos del mediodía. Los de la noche son, en este sentido, unos informativos más personalistas, más "de autor". En cambio sus homólogos del mediodía acostumbran a ser más neutros en lo que a preponderancia de los presentadores se refiere. De ahí que normalmente la opinión pública recuerde más frecuentemente y más fácilmente a los conductores de los informativos de la franja horaria nocturna que a los de la franja de sobremesa. Con ello queremos indicar que cada programa es consecuencia del trabajo de sus profesionales y responsables al frente de la información pero que, a su vez, cada programa es identificable por si mismo y por su cadena, independientemente de sus contenidos informativos.

Es por ello que creemos factible analizar la posición de los rótulos digitales en las noticias diarias de la televisión. Para ello hemos establecido 5 variables.

1. Totalidad: Es el número total de rótulos que aparecen en el teleinformativo. El ejercicio contable incluye los rótulos simultáneos, es decir, cuando aparecen a la vez distintos rótulos en la pantalla.

2. Duración: Es el tiempo, en segundos, que aparece cada rótulo en pantalla.

3. Simultaneidad: Como hemos comentado anteriormente es muy común que aparezcan diversos rótulos simultáneamente — juntamente — en la pantalla.

4. Tipología y tamaño del texto: No todas las letras que podemos leer en la pantalla del televisor tienen el mismo tamaño ni tipo de letra. Normalmente variará según la cadena de emisión y según la función de los enunciados en cada noticia.

5. Ubicación en la pantalla. Es el espacio dónde se lee cada rótulo a los ojos del telespectador. Hay 5 variantes.

5.1. Inferior izquierda. Es la posición más habitual porque también es la situación más recurrente de lectura, de izquierda a derecha.

5.2. Inferior centrado. Generalmente se utilizan en los titulares y en noticias relacionadas con los deportes —resultados, clasificaciones...-.

5.3. Superior izquierda o derecha.

5.4. Centrado. Los enunciados están situados en el centro de toda la pantalla.

5.5. Posterior. En este caso los rótulos aparecen detrás del conductor del teleinformativo, mientras se está informado precisamente de esa noticia. El presentador puede estar de pie o sentado.

\section{Resultados y primeras conclusiones}

Veamos un modelo de análisis. Se realiza a partir de dos teleinformativos, de dos cadenas distintas — una privada y otra pública-; de dos ámbitos territoriales distintos - España y Catalunya - pero de un mismo día y de una misma edición: 
A3 Noticias 2, en adelante A3N2 y Telenotícies Vespre de TV3, en adelante TNV. ${ }^{3}$ En un primer nivel de análisis obtenemos los primeros resultados. ${ }^{4}$

1) La duración de ambos programas informativos es parecida. A3N2 dura 41 minutos y 14 segundos. La duración del TNV es de 38 minutos y 15 segundos.

2) A pesar de esta igualdad en su duración, la presencia y las funciones de los rótulos en los respectivos teleinformativos varían notablemente. En el teleinformativo de A3N2 aparecen 184 rótulos. En TNV, casi el doble, 347 chyrons. ${ }^{5}$ La cadena catalana, pues, aporta mucha mayor información textual en la pantalla.

3) La duración de los rótulos en pantalla también es distinta. El tiempo medio de un rótulo en pantalla en una noticia de $\mathrm{A} 3 \mathrm{~N} 2$ es de 8,97 segundos. Por su parte la duración media de un rótulo en TNV es de 5,35 segundos. La aparición de los chyrons en la cadena catalana es mucho más fugaz que en la cadena privada.

4) En ambos casos es habitual la aparición simultánea de más de un enunciado en la pantalla. Sin embargo, el mayor número de rótulos emitidos en la cadena catalana provoca que éstos sean más numerosos en una misma pantalla. En TNV sólo en 12 ocasiones aparece un único enunciado y son comunes las imágenes con 3 y 4 rótulos simultáneos. En A3N2 hay 21 ocasiones en que sólo aparece un rótulo en la

5) En los dos enunciados utilizan excepto en los alguna noticia estos dos últimos pantalla.

los rótulos acentúan la personalidad de cada teleinformativo teleinformativos los letra minúscula, titulares y en destacada. En casos se utilizan las mayúsculas o cuerpo de letra
mayor. A destacar que A3N2 acentúa 16 enunciados con un tamaño de letra especialmente grande.

6) También en ambas cadenas una mayoría de los rótulos están en la parte inferior izquierda de la pantalla, algo lógico por cuanto es el sentido correcto de lectura de un texto. De izquierda a derecha. A pesar de ello, hay que advertir que hay enunciados que no siguen esta lógica. Los hay en la parte superior izquierda y derecha, centrados, en la parte posterior — detrás de los presentadores - y en la parte inferior derecha — en caso de simultaneidad, por ejemplo-, y para informar de los resultados de un encuentro o de otro acontecimiento público-.

7) La tipología de los rótulos es parecida entre ambas cadenas pero no así su función. Naturalmente en ambos teleinformativos hay rótulos de situación, de temporalidad, de identificación y de presentación, los cuatros tipos de enunciados mayoritarios. Y en cada noticia, cada rótulo de este tipo cumple su función. Pero cuando se tienen en cuenta todas las variables que hemos señalado en los apartados anteriores, aparecen las diferencias. En general, observamos que TNV utiliza los rótulos según su estricta funcionalidad, de un modo más clásico, simultaneándolos entre si y enriqueciendo la información a través de la lectura de la pantalla del televisor. Hay un cierto equilibrio entre aquellos rótulos de temporalidad

\footnotetext{
${ }^{3}$ Emisión del jueves 9 de diciembre del 2010.

${ }^{4}$ Esta investigación es en parte fruto del trabajo de captura y trascripción de los rótulos de dos informativos diarios realizados por parte de los alumnos J. Amores;D.lbarz;A.Muratet, V. Pastor y L.Peiron, en el marco de la asignatura "Lenguaje periodístico: televisión" del Grado de Periodismo de la Facultad de Comunicación Blanquerna de la Universidad Ramón Llull.
} 
y estacionalidad y aquellos de matiz más informativo, dentro de un formato más clásico aunque de apariencia moderna.

A3N2 emite muchos menos rótulos, especialmente aquellos que determinan geográficamente y temporalmente la acción de las noticias. La cadena privada incrementa los enunciados breves o muy breves, a modo de flash y a menudo con expresiones que sólo son inteligibles si se complementan con la información oral y visual que proporciona el propio teleinformativo. Es el caso, por ejemplo, de enunciados como "Agua por todas partes" o "Hasta las puertas del Parlamento".

8) Ambos teleinformativos utilizan símbolos e instrumentos visuales que refuerzan la imagen corporativa de cada cadena. La bola del mundo aparece 67 veces en el TNV, mientras que en A3N2 la imagen corporativa luce detrás del conductor principal. En A3N2 y en el minuto 38 también aparece la dirección de la página web en la parte superior de la pantalla.

La conclusión básica de este modelo de análisis de dos teleinformativos nos indica que los rótulos acentúan la personalidad de cada teleinformativo. En el TNV tienen una función más estrictamente informativa, complementaria y dinámica. Sus numerosos enunciados refuerzan la potencialidad informativa de la cadena, a través de la presencia de los profesionales sobre el terreno y en directo. En A3N2 los rótulos son menos numerosos y pretenden destacar y acentuar el contenido del mensaje informativo con un impacto audiovisual mayor.

\section{Conclusiones finales}

Este trabajo de investigación ha permitido establecer unas líneas maestras metodológicas para estudiar desde una perspectiva académica los rótulos de los programas informativos diarios de las grandes cadenas de televisión que emiten en España. Creemos haber justificado que es factible y necesario el estudio de los enunciados de las noticias, del mismo modo que hay investigaciones sobre las infografías o sobre los contenidos informativos de las mismas.

Una aplicación práctica ha legitimado el objetivo principal que no es otro que el haber demostrado que las nuevas tecnologías han multiplicado el número y la función de los rótulos de las noticias diarias de televisión. Asimismo hemos constatado que los rótulos forman parte intrínseca de la información audiovisual y que, junto con todas sus posibilidades - función, duración, simultaneidad, tipología, ubicación, y en general su visualización en la pantalla del televisorayudan a definir la personalidad de cada informativo.

Por todo ello, no nos parece aventurado afirmar que, con la nueva televisión digital, la televisión no sólo se ve y se escucha, sino que también se lee.

\section{BIBLIOGRAFÍA}

GARCÍA AVILÉS, José Alberto. El periodismo audiovisual ante la convergencia digital. Elche: Universidad Miguel Hernández. 2006.

GIMENO, Gemma; PERALTA, Miquel; JAUSET, Jordi A. El lenguaje de las noticias de televisión. Las audiencias en la televisión. Barcelona: Editorial UOC. 2008.

LARRAÑAGA, José. Redacción y locución audiovisual. Escribir noticias para la radio y televisión. Bilbao: Universidad del País Vasco. 2006. 
LEON, Bienvenido. Telerealidad. El mundo tras el cristal. Sevilla: Comunicación Social. Edicions y Publicaciones. 2009.

MAYORAL, Javier (coord.). Redacción periodística en televisión. Madrid: Editorial Síntesis. 2008.

OLIVA, Llúcia; SITJÀ, Xavier. Las noticias en radio y televisión. Barcelona: Ediciones Omega. 2007.

PERALTA, Miquel. Teleinformatius.La transmissió televisiva de l'actualitat. Barcelona: Editorial Trípodos. 2006.

SHOEMAKER, P.J.; EICHHOLZ, M.; KIM, E.;WRIGLEY, B. "Individual and routine forces in gatekeeping", Journalism Mass Communication Quarterly. Columbia, Summer 78/2. 2001.

VALERO, José Luís: "La infografía periodística y documental impresa". 2010.

VALERO, José Luís. La infografía: técnicas, análisis y usos periodísticos. Barcelona: Universitat Autònoma de Barcelona. 2001.

VILALTA, Jaume. El reportero en acción. Noticia, reportaje y documental en televsión. Barcelona: Edicions Universitat de Barcelona. 2007. 